\title{
RESUMO
}

\section{SEXUALIDADE DA MULHER E TABU NO AMBIENTE ESCOLAR: UMA REVISÃO DA LITERATURA}

SEXUALITY OF WOMEN AND TABLE IN THE SCHOOL ENVIRONMENT: A LITERATURE REVIEW

SEXUALIDADDE MUJERES Y TABÚ ENEL ENTORNOESCOLAR: UNA REVISIÓN DE LA LITERATURA
Sônia Beatriz dos Santos ${ }^{1}$

Isadora Faria Lacerda ${ }^{2}$

\section{DOSSIÊ:}

"CORPO, GÊNERO E SEXUALIDADE NA CIBERCULTURA: MODOS DE CONHECER, PRÁTICAS DE SOCIABILIDADE E REDES EDUCATIVAS"
0 presente artigo se constitui numa revisão bibliográfica sobre a sexualidade da mulher vivenciada no ambiente escolar. Foi realizada no banco de teses e dissertações da CAPES e da Base Scielo de periódicos. Ao analisar a produção acadêmica encontrada, observou-se que a sexualidade da mulher ainda é vista como tabu dentro das escolas e bastante invisibilizada no meio acadêmico. Conclui-se que há um longo caminho a ser percorrido e a necessidade urgente de mudanças por parte das instituições educacionais.

\section{PALAVRAS-CHAVE}

Sexualidade. Mulher. Ambiente Escolar. 


\section{ABSTRACT}

This article is a bibliographical review about the sexuality of women experienced in the school environment. It was held in the Data basis of theses and dissertations of CAPES and in the Data basis of Scielo of journals. When analyzing the academic production found, it was observed that women's sexuality is still seen as taboo within schools and quite invisible in academia. It follows that there is a long way to go and the urgent need for change by the educational institutions.

\section{KEYWORDS}

Sexuality. Woman. School Environment.

\section{RESUMEN}

Este artículo es una revisión bibliográfica sobre la sexualidad de las mujeres experimentadas en el ambiente escolar. Se llevó a cabo en el banco de tesis y disertaciones de CAPES y Base Scielo de revistas. Al analizar la producción académica encontrada, se observó que la sexualidad de las mujeres todavía se considera un tabú dentro de las escuelas y es bastante invisible en la academia. Se deduce que hay un largo camino por recorrer y la necesidad urgente de cambio por parte de las instituciones educativas.

\section{PALABRAS CLAVE}

sexualidad; Mujer; Ambiente escolar. 


\section{INTRODUÇ̃̃̃o}

As Ciências Sociais e Humanas demonstram que os papéis de gênero estabelecidos numa sociedade, exercem grande influência sob a sexualidade. Esta por seu turno, tem sido conceituada como produto de construções culturais acerca dos prazeres e de trocas sociais e corporais que compreendem aspectos como "o erotismo, o desejo e o afeto até noções relativas à saúde, à reprodução, ao uso de tecnologias e ao exercício do poder na sociedade” (CEPESC; SPM, 2009, p. 112).

Nas Ciências Sociais as conceituações contemporâneas de sexualidade envolvem "significados, ideais, desejos, sensações, emoções, experiências, condutas, proibições, modelos e fantasias que são configurados de modos diversos em diferentes contextos sociais e períodos históricos"; de modo que, esta é uma noção dinâmica que vai se modificando e que perpassa por distintos usos, interpretações plurais e contradições e que, por fim, se constitui como objeto de debates e disputas políticas diversas (CEPESC; SPM, 2009, p. 112).

Mediadas por noções de gênero e sexualidade, as mulheres têm seus corpos e comportamentos controlados por um regime patriarcal que limita seus direitos e liberdades. Particularmente, no caso da mulher, a sexualidade tem sido utilizada como um meio de disseminar preconceitos e violências contra o comportamento feminino.

Para garantir os direitos das mulheres à liberdade sexual, é necessário desconstruir paradigmas baseados na misoginia e no machismo presentes na sociedade. E neste sentido, é fundamental que a escola assuma sua responsabilidade na construção e implementação de práticas e projetos educativos e preventivos que conscientizem estudantes, profissionais da educação e familiares sobre como estas formas de opressão produzem desigualdades e vulnerabilidades sociais para as mulheres.

Este artigo é fruto do trabalho de monografia desenvolvido para o curso de Pedagogia da Faculdade de Educação da Universidade do Estado do Rio de Janeiro (UERJ) concluído em 2017. 0 Trabalho propunha realizar uma leitura crítica das práticas escolares repressoras sob a perspectiva do tema da sexualidade (feminina) na escola, buscando entender em que ponto estas precisam ser transformadas. Deste modo, a presente reflexão consiste numa pesquisa bibliográfica sobre a temática da sexualidade da mulher vivenciada no ambiente escolar como um tabu.

A pesquisa foi realizada no período de 2014 por meio de levantamento das produções nacionais publicadas no Banco de Teses e Dissertações da CAPES e na Base do Scielo, buscando-se a partir do ano indicado, trabalhos produzidos nos últimos cinco anos. E foram utilizados os seguintes descritores: comportamento, diversidade sexual, educação da mulher, educação sexual, gênero, mulher, repressão, sexismo, sexualidade, sexualidade feminina, sexualidade da mulher. Foram encontradas, ao todo, cento e trinta e três trabalhos entre teses e dissertações, das quais, apenas dezesseis relacionavam-se, de fato, em algum aspecto, com a temática deste trabalho e, portanto, apenas essas foram selecionadas para análise.

Os resultados das buscas pelos descritores "mulher", "gênero" e "sexualidade" foram os mais numerosos, entretanto, poucas destas teses relacionavam-se especificamente à sexualidade da mulher. Já com o uso de termos mais específicos, como "sexualidade feminina" e "sexualidade da mulher", não foram obtidos resultados, indicando a invisibilidade do tema para a pesquisa acadêmica. Tal re- 
sultado, por si só, já é sintomático e parece ratificar a ideia do tabu em torno da sexualidade feminina. Entretanto, com o uso do termo "educação sexual" como descritores, surgiram resultados que permitem analisar como a questão da sexualidade da mulher vem sendo abordada nas escolas.

Foram encontradas quatro estudos que discutem tal abordagem, sendo três dissertações de mestrado: Educação sexual no ensino de ciências: um estudo com foco nos professores (SILVA, 2012), Os patamares de adesão das escolas à Educação Sexual (COSTA, 2011), Diversidade sexual nas escolas: rumos, possibilidades e desafios (MORAIS, 2012), e um artigo: Educação e Sexualidade: a compreensão de professoras de ciências e biologia sobre a diversidade sexual (YALIN; LOCKS, 2011). Todos os estudos parecem apontar os mesmos indícios e levar a uma mesma conclusão sobre a abordagem da questão da sexualidade feminina nas escolas, que é preocupante - a impossibilidade da temática na pesquisa acadêmica.

Consideramos importante, ressaltar que, precedentemente, ao trabalho de pesquisa para elaboração da monografia (em 2017), foi realizado em 2014, como já indicado, um levantamento no Banco de teses e dissertações da CAPES de produções dos últimos cinco anos, que considerou inicialmente, apenas os descritores "educação da mulher" e "comportamento", desta busca foram encontrados as teses: A mulher deve ser bela, deve ter graças e encantos: educação de salão na São Luís republicana (1890-1920) (SILVA, 2011), Mulheres e revistas: a dimensão educativa dos periódicos femininos Jornal das Moças, Querida e Vida Doméstica nos anos 1950 (SANTOS, 2011), e Educando mulheres, vendendo saúde: Propagandas e outros textos de jornais curitibanos dos anos 1920 (CONCEIÇÃO, 2012).

A fim de refletir sobre a temática proposta, primeiramente, discutiremos a imposição de um padrão de sexualidade as mulheres; em segundo refletiremos sobre a questão do tabu em torno da sexualidade da mulher; nas seções três e quatro, analisamos respectivamente, o papel da escola na desconstrução do padrão de sexualidade, e as considerações finais.

\section{A IMPOSIÇÃO DE UM PADRÃO}

Os papéis de gênero socialmente construídos e impostos englobam diversos campos da vida dos indivíduos. No caso das mulheres, esses padrões são opressores já que, caso não sejam seguidos, geram discriminação e marginalização de diversas formas. Apesar de cientistas sociais como Margaret Mead terem enfatizado que "não existe uma relação direta entre o sexo do corpo e a conduta social de homens e mulheres" (CEPESC; SPM, 2009, p. 45), continua-se atribuindo ao gênero feminino uma forma específica de se comportar em relação à sexualidade.

É importante ressaltar que as imposições em torno do comportamento sexual existem tanto para as mulheres cisgênero quanto para as mulheres transgênero, porém são diferentes em cada situação ${ }^{3}$. Enquanto da mulher cisgênero espera-se a castidade em determinada faixa etária, a heterossexualidade, a prática sexual, visando à maternidade e determinado recato ao tratar de assuntos sexuais, da mulher transgênero a sociedade espera que corresponda ao estereótipo preconceituoso que em torno dela foi criado. Tal estereótipo coloca a mulher transgênero como um fetiche, associando-a a atos considerados promíscuos e tornando-a objetificada. 
Em ambos os casos, a quebra do padrão esperado pode acarretar discriminação. Os padrões de "como ser mulher" são reproduzidos e naturalizados pelas mídias (LOURO, 2008), instituições religiosas, instituições de Educação e em inúmeros outros espaços e organizações que atuam como influentes formadoras de opinião. Padrões de regulação do comportamento das mulheres podem ter sido modificados em alguma medida para se ajustarem melhor à realidade social, econômica ou cultural de um período histórico determinado. Entretanto, estes jamais foram erradicados totalmente.

A pesquisa prévia realizada no banco de teses e dissertações da CAPES no ano de 2014, cujos descritores foram "educação da mulher" e "comportamento" apresentou resultados que demonstram o caráter histórico da associação entre a educação de uma mulher e sua inserção nos padrões sociais estipulados. Foram encontrados três trabalhos que abordavam o tema por essa perspectiva.

As teses A mulher deve ser bela, deve ter graças e encantos: educação de salão na São Luís republicana (1890-1920)(SILVA, 2011), Mulheres e revistas: a dimensão educativa dos periódicos femininos Jornal das Moças, Querida e Vida Doméstica nos anos 1950 (SANTOS, 2011) e Educando mulheres, vendendo saúde: Propagandas e outros textos de jornais curitibanos dos anos 1920 (CONCEIÇÃO, 2012) mostram que, pelo menos desde os anos 1890, no Brasil, a educação das mulheres atuava de modo a reprimir comportamentos que se afastassem do ideal de recato, delicadeza e docilidade. Atualmente, essa repressão se tornou menos explícita e os termos utilizados para caracterizar o ideal social de mulher passaram a se apresentar, muitas vezes, em eufemismos. Porém, ela ainda existe fortemente em grande parte das instituições escolares.

Ao analisar os textos de reportagens e colunas destinados ao público feminino (e considerados de natureza educativa), publicados em 1920 nos jornais Gazeta do Povo, O Dia (de Curitiba) e Diário da Tarde, Conceição (2012) revela a existência de forte discurso que instituía que as mulheres deveriam atender a um ideal de recato e adequação do comportamento sexual, que era apresentado como condição direta e fundamental para a felicidade da família da mulher em questão. Deposita-se sobre essa mulher não só a responsabilidade de ter que se adequar a um padrão de "ser mulher", mas também a culpabilização dela caso não atendesse a tais condutas, ao afirmar que seu comportamento em relação à sexualidade não era uma questão particular, mas sim de toda a família.

\section{TABU EM TORNO DA SEXUALIDADE DA MULHER}

É possível observar cotidianamente que os insultos e ofensas dirigidos às mulheres estão, quase sempre, ligados à sua sexualidade. Se a mulher assume um comportamento sexualmente ativo, esta pode ser nomeada em determinadas sociedades, como as ocidentais: "puta”, "galinha”, "piranha", dentre outros adjetivos estereotipados. Mas elas, também, podem ser chamadas de "'sapatões', 'machonas' ou 'freiras' (como categoria de acusação em alusão à castidade para as que se recusam a aderir à prática sexual por imposição do parceiro)" (CEPESC; SPM, 2009, p. 52). 0 exercício livre da sexualidade feminina é visto como um tabu, quando difere daquilo que uma determinada sociedade estabeleceu como comportamento sexual padrão e aceitável paras estas que vivem sob suas regras. 
O fato de não se tentar desconstruir o padrão opressor imposto sobre o comportamento sexual da mulher, tratando-o como tabu, gera abusos e violências sexuais. Diante dessa realidade, é preciso analisar qual deveria ser o papel da instituição escolar, visto que atua como formadora de ideais julgamentos. Entretanto, quando se observa a maneira como o ambiente escolar vem tratando a questão da sexualidade feminina, o resultado é preocupante, pois, na maioria dos casos, a escola parece estar corroborando com os padrões sociais opressores e colaborando para que eles se mantenham.

\section{SEXUALIDADE DA MULHER E AMBIENTE ESCOLAR}

Quando uma questão se torna um tabu social, ela é invisibilizada, deixando de ser discutida e analisada, fazendo com que os preconceitos acerca da mesma cresçam ao invés de serem erradicados. Tendo conhecimento da violência sofrida histórica e cotidianamente pelas mulheres, em geral justificada na crença em valores heteronormativos, é necessário que as causas que levam à esta sejam descobertas e combatidas.

A escola não pode ignorar as questões de gênero e de sexualidade e precisa repensar o modo de abordá-las, uma vez que não se pode esquecer que o currículo das instituições escolares foi inicialmente pensado pelo homem branco heterossexual, carregando consigo o seu ponto de vista (LOURO, 2008). Consideramos que, se a escola não aborda em seu currículo o tema da sexualidade da mulher, tal ausência contribui com a manutenção de preconceitos e discriminações que as expõe a violência.

É, ainda, um papel da escola, possibilitar a transformação de estruturas sociais opressoras (FREI$\mathrm{RE}, 1996)$, de modo que o ambiente escolar deveria atuar contra a repressão da sexualidade feminina que difere do padrão estipulado, já que ao, reprimir, também se oprime e marginaliza mulheres.

É necessário frisar que "é a sociedade, e não a biologia ou os genes, quem determina como devemos ser e nos comportar, quais são as nossas possibilidades e nossos limites" (MORENO, 1999, p. 28). 0 rompimento com o tabu em torno da sexualidade feminina depende, em grande parte, da forma como o ambiente escolar lida com esta questão e aborda o tema. Entretanto, o que se pôde observar por meio da análise dos resultados da pesquisa no Banco de Teses e Dissertações da CAPES, foi que o tema ainda é pouco discutido e, quando se faz presente nas instituições escolares, tende a ser abordado de forma pouco eficiente no combate aos preconceitos que o rodeiam.

As teses encontradas sobre o tema da educação sexual nas escolas foram: Educação sexual no ensino de ciências: um estudo com foco nos professores (SILVA, 2012), Os patamares de adesão das escolas à Educação Sexual (COSTA, 2011), Diversidade sexual nas escolas: rumos, possibilidades e desafios (MORAIS, 2012). Estes trabalhos nos permitiram, nos revelaram diversos aspectos importantes acerca da abordagem da sexualidade feminina no ambiente escolar. Os estudos apresentam informações sobre escolas localizadas nos estados brasileiros do Espírito Santo, Paraná, Rio de Janeiro e Santa Catarina. Foi analisada, em diversos aspectos, a maneira como tais escolas educavam seus alunos e suas alunas em relação à sexualidade.

Nenhuma das quatro teses trata, especificamente, de questões da sexualidade da mulher. A se- 
xualidade aparece nesses trabalhos sob uma visão ampla do tema. Foi possível observar que, de modo geral, não há, nas escolas em questão, uma preocupação social, orientando as abordagens dos temas ligados à educação sexual, sendo tais abordagens predominantemente médico-higienistas ou baseadas em preceitos morais socialmente pré-estabelecidos.

Em algumas das escolas onde se deram tais pesquisas, sequer foram observadas medidas intencionais por parte da instituição escolar para lidar com temas relativos à sexualidade. Representantes de algumas dessas escolas, inclusive, discordaram do fato de a sexualidade ser um tema de responsabilidade da instituição escolar (COSTA, 2012). No entanto, é necessário frisar que "segundo os Parâmetros Curriculares Nacionais, é de suma importância incluir a orientação sexual como tema transversal nos currículos escolares" (MORAIS, 2012, p. 1).

Nos casos em que foi observada alguma preocupação social atrelada à abordagem da educação sexual em determinadas escolas analisadas, tratava-se de questões ligadas ao combate à homofobia, porém foram citados apenas casos de combate ao preconceito contra homens homossexuais, de modo que a homossexualidade de mulheres ficou invisibilizada. Este pode ser considerado um dos traços da sexualidade feminina vista como tabu nas escolas.

Foram relatados, em alguns dos trabalhos analisados, que determinadas escolas realizavam atividades educativas em torno do tema da sexualidade, porém convidando profissionais da área de saúde, os quais não eram funcionários da instituição, para abordarem o tema no lugar de professoras e professores.

Essa iniciativa é problemática, pois volta a relacionar e limitar a sexualidade à perspectiva médico-higienista, em vez de considerá-la, também, como uma questão sociocultural e pessoal. Além disso, ao incumbir um profissional que não trabalha na escola e não conhece as alunas e os alunos, promove-se um distanciamento do discurso, que pode se tornar ainda mais técnico por estar partindo de alguém que desconhece a realidade específica dos estudantes daquela determinada escola.

Ao longo da análise das teses encontradas na pesquisa, também foram recorrentes os relatos de tensões por parte de professores e professoras ao lidar com questões relacionadas à sexualidade em geral e a visão estereotipada que estes profissionais apresentavam, em muitos casos, em relação aos papéis de gênero socialmente estipulados, os quais incluem um padrão de comportamento sexual para homens e mulheres.

É preocupante que profissionais da Educação ainda apresentem um olhar de senso comum para essas questões, pois, desse modo, a desconstrução de tais paradigmas e visões pré-concebidas, a qual deveria ser uma das funções da escola, torna-se praticamente impossível.

Por fim, foram também relatadas, situações explícitas de preconceito por parte de professores e professoras em relação à sexualidade de alunas e alunos, principalmente nas escolas analisadas que ficam no estado do Rio de Janeiro. Nesses casos, a instituição escolar não está apenas descumprindo seu papel de desconstrução dos padrões, mas também estimulando e propagando ideias sexistas e contribuindo com a violência física e social das quais são vítimas as mulheres que fogem aos padrões pré-estabelecidos para seu comportamento sexual.

Como se pôde observar, a maneira como a instituição escolar vem lidando com a sexualidade, em particular com a sexualidade da mulher, é problemática, uma vez que não foram registradas quaisquer intervenções, visando o combate aos preconceitos que rodeiam a sexualidade feminina em nenhuma das instituições pesquisadas nos quatro estudos. 
Essa ausência de discussão em torno do tema demonstra o quanto isto ainda é um tabu nas escolas e a enorme dificuldade que ainda precisa ser enfrentada para que a instituição escolar, em sua grande responsabilidade de formar opiniões, assuma um papel de incentivo ao questionamento e de desconstrução dos paradigmas sociais que levam à discriminação e a manifestações de violência de diversos aspectos contra as mulheres que apresentam sexualidades diferentes do padrão socialmente cobrado.

A abordagem técnica e a visão médico-higienista que as escolas apresentaram em relação ao tema da sexualidade, levaram a questão da prevenção de gravidez na adolescência a ser a única temática direta e especificamente relacionada à sexualidade feminina, a ser apresentada às alunas e aos alunos. A discussão da gravidez na adolescência, quando tomada por um ângulo apenas de prevenção e sem abertura para a desconstrução de visões estereotipadas da adolescente que se torna mãe, tende a induzir as estudantes a evitarem a prática sexual até determinada idade, levando-as, implicitamente, a reprimirem desejos e curiosidades. Pode levar, ainda, a manutenção do preconceito para com as mulheres que iniciam a vida sexual antes de atingirem a fase adulta, corroborando com a discriminação e marginalização delas.

Em nenhuma das quatro teses, houve registro de qualquer intervenção, discussão ou introdução ao tema da cultura do estupro, seja de forma direta ou indireta. É preocupante que não exista, no ambiente escolar, uma abordagem desse tema, uma vez que historicamente, o abuso sexual sofrido por mulheres é tratado de forma naturalizada e faz-se fundamental que a escola ofereça a seus alunos e alunas a oportunidade de desconstruir essa perspectiva, tendo em vista a responsabilidade desta instituição na formação cidadã e a necessidade de se garantir a segurança das mulheres, que são cotidianamente vítimas do crime em questão.

A não desconstrução da cultura do estupro, histórica e, ainda atualmente, entranhada em nossa sociedade, corrobora com a manutenção deste ciclo opressor e criminoso, que apresenta, também, implicitamente, caráter de repressão. A cultura do estupro atua de forma repressora à vivência de uma sexualidade considerada socialmente "promíscua" para as mulheres, uma vez que, naturalizando o abuso sexual, culpabiliza a vítima pelo acontecimento do crime.

Faz parte da cultura do estupro afirmar que mulheres que "se dão ao respeito" ou que são "recatadas” não sofrem violência sexual, embora tal afirmativa seja totalmente falaciosa. Com isso, a sociedade reprime, indiretamente, qualquer desejo feminino de desvio do padrão de comportamento sexual estipulado para seu gênero e, ao não desconstruir essa cultura, a instituição escolar assume um papel de ratificar a repressão.

Apesar da marginalização mais explícita, não são apenas as mulheres de comportamento considerado socialmente "promíscuo" que sofrem com a cultura do estupro. Ao não abordar a sexualidade da mulher por uma perspectiva sociológica, a escola prejudica, também, mulheres que escolhem manter sua virgindade e mulheres que possuem relacionamentos com outras mulheres. Isso ocorre, porque faz parte do comportamento sexual padrão criado para a mulher, servir a um parceiro.

Ao longo dos séculos, perpetuou-se a ideia de que a mulher faz sexo por apenas duas razões: visando à maternidade e para satisfazer o homem com quem se relaciona, de modo que tais razões se confundem, ainda, com obrigações. A posição de submissão da mulher na sociedade heteronormativa faz com que homens cresçam acreditando que é um dever feminino ceder e estar disponível para o ato 
sexual sempre que for da vontade deles.

É necessário que a escola atue desconstruindo essa ideia, para que seus alunos tenham em mente que não possuem o direito de forçar relações sexuais com nenhuma mulher e as alunas tenham consciência de seu direito de não quererem fazer sexo (seja ao longo da vida ou apenas em determinado momento) independente da vontade de algum homem. Essa desconstrução beneficia, ainda, as alunas lésbicas, ao desvincular a prática sexual do desejo masculino, combatendo a visão preconceituosa de que a mulher precisa do homem para fazer sexo, contribuindo para naturalização da prática sexual entre mulheres.

A ausência de atividades com intenção de quebrar preconceitos e estereótipos sobre a sexualidade da mulher transgênero, também foi uma marca nas abordagens de educação sexual das escolas dos quatro diferentes estados brasileiros. Em uma das teses, inclusive, foi citado um caso em que uma professora, aparentemente, por ignorância e não por má fé, orientou uma aluna transexual ${ }^{4}$ a procurar um psiquiatra para que o profissional a ajudasse a se convencer de que ela era, na verdade, um homem (BRIZOLA; LOCKS, 2012).

Na fala da professora, é possível perceber sua falta de informação a respeito do assunto, pois ela acredita que a aluna seja um aluno homossexual, embora a estudante afirme, explicitamente, ser uma mulher. É problemático que profissionais de educação não recebam, ao longo de sua formação, orientações a respeito de um tema como a transexualidade, tendo em vista todos os preconceitos que as pessoas trans sofrem diariamente, principalmente as mulheres, as quais, além de serem julgadas como "anormais", são frequentemente objetificadas e vistas apenas como fetiches.

Ficou evidente, com a análise da pesquisa feita em cada tese lida, que as escolas estudadas nos quatro estados brasileiros em questão, tratam de forma muito semelhante e preocupante a questão da sexualidade feminina e que este tema ainda pode ser fortemente considerado um tabu na instituição escolar. Faz-se necessário, portanto, discutir as origens e as causas dessa falha da escola em cumprir com sua função de desconstrução libertadora, defendida por Freire (1996), bem como possíveis soluções para o problema.

De acordo com o que se pôde analisar a respeito da abordagem que escolas de quatro diferentes estados brasileiros vêm fazendo sobre o tema da sexualidade da mulher, ainda existem muitos obstáculos a serem superados para que a sexualidade feminina deixe de ser vista como tabu no ambiente escolar e passe a ser discutida sob diferentes pontos de vista, deixando de lado os olhares estereotipados e as falas que reproduzem o senso comum e carregam preconceitos.

Mesmo nas escolas em que havia, no currículo, questões de educação sexual, não foram percebidas preocupações sociais ou individuais em relação às alunas e aos alunos. A ausência de discussões e debates a respeito da sexualidade feminina e de temas socioculturais atrelados a esta temática mostrou o quanto ela ainda é invisibilizada.

Não se pode esquecer que, como já foi afirmado anteriormente, o currículo das instituições escolares foi, inicialmente, pensado tendo como parâmetros o homem branco e heterossexual (LOURO,

4 Transexual: pessoa que possui uma identidade de gênero diferente do sexo designado no nascimento. Homens e mulheres transexuais podem manifestar o desejo de se submeterem a intervenções médico-cirúrgicas para realizarem a adequação dos seus atributos físicos de nascença (inclusive genitais) à sua identidade de gênero constituída (CEPESC; SPM, 2009, p.128). 
2008) e, sendo assim baseia-se nos interesses e perspectivas deles. Em geral, o homem heterossexual enxerga a sexualidade da mulher como algo nulo e totalmente dependente dele.

Em algumas das escolas que sediaram as pesquisas das teses, professores e professoras admitiram que se sentiam desconfortáveis e tensos ao lidar com temas referentes à educação sexual. É possível que esses profissionais carreguem preconceitos sociais justamente devido ao fato de não terem passado por processos de desconstrução deles nas instituições escolares em que estudaram, constituindo neste caso, um círculo vicioso.

É provável, ainda, que durante sua formação profissional, não tenham ocorrido contato com discussões a respeito do tema, nem orientações sobre como trabalhá-lo. No caso específico das professoras, pode haver, também, um motivo peculiar para a falta de preparo em lidar com a sexualidade. Pelo fato de serem mulheres, é provável que essas professoras tenham sofrido repressões à sexualidade ao longo da vida.

Ocorre, também, nas escolas observadas, uma limitação da abordagem da sexualidade em geral, apenas por uma perspectiva técnica e médico-higienista. A errônea associação das questões sexuais apenas aos temas da saúde faz com que todos os aspectos sociais e culturais que circundam o sexo sejam ignorados e, consequentemente excluídos do currículo escolar. 0 sexo passa a ser tratado como algo mecânico, restringindo-se a uma condição para reprodução, reforçando os padrões de gênero impostos à mulher e encobrindo a complexidade em torno do tema da sexualidade feminina.

Ao encarregar apenas professores e professoras de Ciências Naturais e Biológicas da abordagem do tema da sexualidade, como se observou nas escolas analisadas, a escola priva as/os estudantes do contato com as demais questões acerca da sexualidade. Desta forma, é preciso que a abordagem da sexualidade feminina pela instituição escolar seja, urgentemente, repensada e reformulada.

Ao analisar as causas que levam esse tema a ser considerado um tabu, torna-se mais fácil, também, pensar em possíveis soluções para os problemas observados. Desconstruir o padrão social estipulado para o comportamento sexual da mulher é fundamental para eliminar preconceitos de cunho machista e ideias misóginas as quais levam a uma série de violências que são cometidas contra as mulheres. A instituição escolar, em seu papel de formadora de opiniões, pode e deve atuar nesse processo de desconstrução adotando, para isso, algumas medidas.

Os Parâmetros Curriculares Nacionais (PCN) apontam a necessidade de se abordar o tema da sexualidade como um tema transversal no ensino e não como um assunto isolado na escola. Ela deve ser vista como uma questão sociocultural que faz parte de cada indivíduo e dele não se separa. Sendo assim, esse tema deve estar presente no currículo enquanto documento escrito e enquanto vivência.

É preciso que os currículos sejam repensados para desconstruir preconceitos acerca da sexualidade. 0 "trabalho de orientação sexual escolar tem de ser pensado numa perspectiva metodológica, interdisciplinar, ou seja, coletivamente” (MORAIS, 2012, p. 5). Além de ser fundamental que a questão da sexualidade perpasse todas as disciplinas escolares, a inclusão e contextualização desta temática na ementa é perfeitamente possível (CEPESC; SPM, 2009).

\section{CONSIDERAÇÕES FINAIS}


A presente discussão nos permitiu compreender que a escola apresenta grande responsabilidade em relação à manutenção ou à quebra de paradigmas sociais que promovem violências. Para que os preconceitos machistas em relação à sexualidade feminina sejam desconstruídos, é essencial que esse processo seja iniciado o mais cedo possível dentro do ambiente escolar.

Concluímos a partir dos estudos levantados que a sexualidade da mulher ainda é percebida como tabu dentro das escolas e ainda invisibilizado no meio acadêmico. Esse resultado demonstrou o longo caminho que ainda precisa ser percorrido e a necessidade urgente de mudanças por parte das instituições escolares, rumo a uma abordagem emancipatória da sexualidade feminina.

A ausência de orientação aos profissionais da educação ao longo de sua formação e, mesmo depois dela, é também um obstáculo dentro da escola para se tratar de questões referentes a sexualidade. E não discutir a sexualidade feminina sob um ponto de vista sociológico, impossibilita que os paradigmas sociais negativos atrelados a esta questão sejam questionados e rompidos.

Finalmente, é preciso repensar o currículo escolar enquanto documento escrito e como vivência cotidiana do ambiente. Ao manter-se indiferente e em silêncio, numa sociedade desigual, machista e patriarcal, a escola corrobora com práticas opressoras que afetam os direitos, as condições de vida e saúde de meninas, jovens e mulheres adultas.

\section{REFERÊNCIAS}

BRASIL. Secretaria da Educação Fundamental. Parâmetros Curriculares Nacionais: apresentação dos temas transversais, ética. Brasília: MEC/SEF, 1997.

CEPESC e SPM. Gênero e diversidade na escola: formação de professoras/es em Gênero, orientação Sexual e Relações Étnico-Raciais. Livro de conteúdo, 2009. - Rio de Janeiro: CEPESC; Brasília: SPM, 2009.

Conceição, Sarasvati Yakchini Zridevi. Educando mulheres, vendendo saúde. Propagandas e outros textos de jornais curitibanos dos anos 1920. Paraná: UFP-PA, 2012, 163p. Dissertação (Mestrado em Educação) - Universidade Federal do Paraná, 2012.

COSTA, Priscila Caroza Frasson. Os patamares de adesão da escola à educação sexual. 2012, 305p. Tese (Doutorado) - Programa de Pós-Graduação em Educação, Faculdade de Educação da Universidade de São Paulo, USP, São Paulo, 2012.

FREIRE, Paulo. Pedagogia da autonomia - saberes necessários à prática educativa. Coleção Saberes. 36. ed. São Paulo: Editora Paz e Terra, 1996.

JOHNSON, Allan G. Dicionário de sociologia: guia prático da linguagem sociológica. Rio de Janeiro: Zahar, 1997. 
LOCKS, G. A.; YARED, Y. B. Educação e sexualidade: a compreensão de professoras de ciências e biologia sobre a diversidade sexual. Percursos, Florianópolis, Santa Catarina, v. 13, n. 2, p. 155-168, jul.-dez. 2012.

LOPES, Alice Casimiro; MACEDO, Elizabeth. Teorias de currículo. São Paulo: Cortez, 2011.

LOURO, Guacira Lopes. Gênero, sexualidade e educação: Uma perspectiva pós-estruturalista. Petrópolis, RJ: Vozes, 1997.

LOURO, Guacira Lopes. 0 corpo educado: pedagogias da sexualidade. Belo Horizonte: Autêntica, 2000.

LOURO, Guacira Lopes. Gênero e sexualidade: Pedagogias contemporâneas. Campinas, SP: Editora da UNICAMP, 2008.

MEAD, Margareth. Sexo e temperamento. São Paulo: Editora Perspectiva, 2000.

MORAIS, Antônio José Pereira de. Diversidade sexual na escola: rumos, possibilidades e desafios. 2012. 110p. Dissertação (Mestrado em Educação) - Universidade Católica de Petrópolis, UCP-RJ, Petrópolis, RJ, 2012.

MORENO, Montserrat. Como se ensina a ser menina: o sexismo na escola. São Paulo: Moderna; Campinas: Editora da Universidade Estadual de Campinas, 1999.

SANTOS, L. P. B. dos. Mulheres e revistas: a dimensão educativa dos periódicos femininos Jornal das Moças, Querida e Vida Doméstica nos anos 1950. 2011, 170p. Dissertação (Mestrado) - Programa de PósGraduação em Educação, Universidade do Estado do Rio de Janeiro, UERJ-RJ, Rio de Janeiro, 2011.

SILVA, C. F. S. A mulher deve ser bela, deve ter graças e encantos: educação de salão na São Luís republicana (1890-1920). 2011, 157p. Dissertação (Mestrado em Educação) -Universidade Federal do Maranhão, Maranhão, MA, 2011.

SILVA, O. A. da. Educação sexual no ensino de ciências: um estudo com foco nos professores. 2011, 121p. Dissertação (Mestrado em Educação) - Setor de Educação, Universidade Federal do Paraná, UFP-PA, Paraná, 2011. 
1 Professora adjunta da UERJ; Pesquisadora Núcleo de Estudos Afro-brasileiros da UERJ (NEAB_UERJ).

E-mail: soniabsantos@yahoo.com

2 Professora da Educação Básica.

E-mail: isadora.lacerda@hotmail.com

\section{(C) (1) ()}

Este artigo é licenciado na modalidade acesso abertosob a Atribuição-Compartilhalgual CC BY-SA

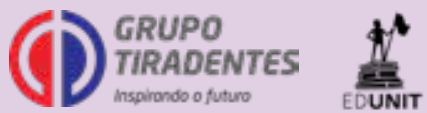


